\title{
Proposing a novel, efficient measure for assessing glade restoration efficacy: wildflower presence and abundance
}

\author{
Adam E. M. Eltorai
}

Department of Biology, Washington University in St. Louis, St. Louis, USA.

Email: aeltorai@gmail.com

Received 8 February 2011; revised 25 May 2011; accepted 26 May 2011.

\begin{abstract}
Human presence is detrimentally affecting natural environments. Glades are an example of such environments. As glades diminish in number, proper restoration efforts are essential for the preservation of the habitats' unique ecosystems, biodiversity and natural processes. To ensure glade survivorship, evaluation of glade restoration efforts is critical. As indicators of the trophic level of producers in a food chain, wildflowers can serve as overall indicators of the restoration process. A comparison of wildflower species presence and abundance between recently restored and control glades offer insights into the restoration progress. In this paper, I propose the usage of a novel method for assessing restoration efficacy. I outline step-by-step how to apply such a method. I then explain how the implementation of such a method can be used to address questions regarding the restoration effort's efficacy.
\end{abstract}

Keywords: Method; Glade; Wildflower; Restoration

\section{INTRODUCTION}

Human population growth has led to deleterious global environmental changes. The degradation of natural environments threatens biodiversity. As a greater number of species move towards extinction, conservation biology and restoration ecology become increasingly important. The two disciplines promote the development of nature reserves and enhance natural environment recovery. Recovery of the natural environment is the only hope for preserving biodiversity. There is an urgent need for scientific advancement in the fields of conservation biology and restoration ecology. Practical restoration efforts must utilize our knowledge of theoretical ecological principals in addition to our developing understanding of empirical restoration ecology [1].

In this study, I will examine one particularly affected natural environment, the glade. Specifically, I will focus on the Missouri Ozark glade, which is representative of the larger Missouri glade population. As rocky clearings in wooded areas, glades are desert-like island ecosystems, home to many unique, interesting, and sometimes rare species of insects, reptiles, mammals, wildflowers, and grasses. Occurring on southwestward facing slopes, glades are categorized by the vegetation-influencing bedrock that lies beneath the thin soil-the most common type in Missouri is the dolomite glade [2]. Ranging approximately from one-tenth hectare to 200 hectares, glades generally are not suitable for tree growth due to the extremely dry and thin soils. Such harsh conditions foster frequent fires [3]. These frequent fires are vital for maintaining the glade habitat, as the fires are able to kill invasive woody vegetation with its susceptible-to-fire, surface root system, while allowing the native glade vegetation, with its deeper-root systems to survive [4]. Without the natural fires, glades are overcome by a canopy of encroaching trees-primarily composed of the Eastern red cedars (Juniperus virginianus). Such an invasion can reduce the light that reaches the native glade grasses and wildflowers, thus degrading and/or destroying the glade habitat.

Ozark glades have experienced degradation in a similar pattern to that of their Missouri counterparts. For example, it is believed that 200 years ago 5\% of Shaw Nature Reserve's 2400 acres was covered by glades. As fire suppression regulations took effect the total glade area dwindled to $1 \%$ [5]. This decline in glade presence prompted reserve leaders to initiate the use of Missouri glade restoration efforts in 1991.

The destruction of glade habitats has been attributed to U.S. Forest Service's fire suppression regulations. Through suppression of naturally-occurring frequent fires, many glades have become overrun by devastating woody vegetation [6]. Additionally, open-grazing was practiced widely in the Ozarks in the 1800s and early 1900s. Such a practice undoubtedly contributed to glade decline [7]. As the glades become scarcer, effective re- 
storative efforts has become an increasingly important issue. Current restoration efforts consist of cutting and removing the Eastern red cedars, inducing a prescribed burn to remove additional invaders, and then sowing locally collected seeds of glade species into the restored areas. Recently developed techniques involve the use of herbicides and directed attack on the stumps of invading species [5].

To ensure glade restorative methods are effective, we must thoroughly examine the progress of the restored glades themselves. To efficiently examine the progress of restored glades, a sufficient measure of glade health must be examined.

Restoration efforts are frequently geared towards reestablishing the habitat's natural vegetation infrastructure [8]. Thus, quantifying wildflower recovery offers insight into not only the producer-level of a habitat but may serve as an indicator for the health of all higher trophic level species in the habitat and the functionality of the community as a whole. Ultimately, a healthy wildflower presence may indicate a healthy glade ecosystem by way of illustrating a healthy food web.

To summarize, the ultimate goal of this study is to propose the usage of a novel, efficient method for determining the efficacy of glade restoration efforts. In this study, I explain how this method can be utilized in further investigations to examine the progress of restored glades. In order to quickly, yet effectively, determine the efficacy of restoration efforts, one needs to utilize readily visible and reliable measures of glade health. In this paper, I put forth the idea of comparing the presence and abundance of wildflowers as the easy yet reliable measure. Given the procedural simplicity, this method promises to be quick and effective for gathering data regarding the health of the land will inevitably serve as an important guide for future land management directions.

\section{SUGGESTED METHODS}

Wildflower species presence and abundance should be measured in matched (with respect to type, size, surrounding forestation, and topography) glades. To examine the restoration efficacy, an equal numbers of restored glades should be compared to pristine glades, which are healthy, free of invasive species, and not in need of restoration. These pristine glades will serve as a control. For a more thorough understanding of the whole process, a proper understanding of the restoration history is essential.

A transect sampling technique can be used in both the restored glade and the pristine control glade. The transect technique enables one to take a large random sample of each glades' wildflower species, thus providing a quantifiable method for examining the recovery of glade wildflowers. To account for the possibility that the burned, restored glade may green up earlier due to absence of overhanging shading effects, one should take equal numbers of samples on both glades' edges where surrounding forestation is nearly identical.

In each glade, transects can be lined up parallel to the glades' edges. Using the transect as a guide, a random numbers table can be used to determine the sequential location and alternating distance from the transect the sampling can occur. When a sampling area falls on a non-glade region, the sample area can be taken the same distance from the transect on the opposite side of the line. $2 \times 2$ meter sample sizes can be taken in each glade. In order to make any comparisons, the sum of sampling area should represent equal portions of the total area of the glades. Wildflower species can be identified on site using a field guide to Ozark wildflowers [9]. If the species could not be identified on-site a picture can be taken for later identification. In each sampling, measure the number of each wildflower species, the average wildflower height, the average height of the non-wild- flower vegetation, the percent shade above the sample, and the percent ground coverage by vegetation in the sampling. The percent of shade above the sample can be measured using percent coverage of circular visual field. The percent of ground covered by vegetation can be measured using percent of sampling grid occupied by any plant life.

The presence and abundance of different wildflower species should be compared between the pristine and restored glades. Employ the use of an unpaired $t$-test for statistical analysis.

\section{SUGGESTED DATA ANALYSIS}

The random transect sampling method reveals similarities or differences in wildflower species distribution in the pristine vs. the restored glades. Examine the number of species of wildflowers that are present in both the pristine and restored glades. Are there certain species only found in one glade and not in the other? Differences in the number of observed wildflower species between the two glades may serve as another indicator of biodiversity.

Examine the abundance of each species. Abundance levels can serve as indicators of a species' viability in a certain environment. To best examine abundance differences, compare the number of individuals of the species found on both glades. Are there unexpected differences in species presence and/or abundance?

It could be useful to compare the two glades using an index of biodiversity. One example is the ShannonWiener (or Shannon-Weaver) diversity index. This index combines information on species richness with relative abundance. Such indices consider communities that are 
approximately evenly divided among nine species to be considered more diverse than communities with nine species in which $95 \%$ of individuals are from one dominant species.

\section{DISCUSSION}

Given the urgent need for restoration of natural environments, effective restoration efforts must be utilized. To determine if the efforts are achieving the desired goals, there is a need to assess the efficacy of the restoration efforts. Thus, the purpose of this paper is to propose a novel, efficient measure of assessing the efficacy of glade restoration efforts. By proposing this practical method, I hope to encourage others to implement this strategy to determine if restoration efforts are adequate or are in need of further refinement.

In order to make definitive conclusions about the efficacy of current restoration efforts, sufficiently large sample sizes should be taken. Similarities between pristine and restored glades' wildflower species presence and abundance can be used as a quick assessment. At one end of the spectrum, the two glade types could be identical. This would suggest that the restoration efforts are returning glades to pristine conditions. At the other end of the spectrum, there could be a huge discrepancy between the two glade types. This finding may suggest that the restored glade may not be on par with the pristine glade with respect to the conditions necessary for proper abundance of all species. Moreover, this may be indicative of a need for improved restoration efforts.

When interpreting the data, there are several additional factors to consider. It is possible, however, that it may take time for wildflower populations to recoverparticularly the uncommon species which may have lower numbers of seeds in the seed bank and the perennials which may remain vegetative as they spend the first few years re-establishing their root systems. The establishment of various forbs may lead to root competition which may affect overall composition and robustness of individual plants, as well. As perennial density increases, they may compete with the annuals which may initially faster to recover. Varying, year-to-year weather patterns may factor into how rapidly flowers response occurs too.

Implementation of this novel measure of glade health opens the doors for further, useful research. Such research may address the success of restoration efforts. To better assess restoration effort efficacy, future research could be done on glades in different regions. Sampling could also be done at more than one time during the growing season. Once a more complete picture begins to develop about the actual variety of species present and their relative abundances on the glades, an important next step would to be to examine more closely what each species can tell us about the overall health of the glade. To do this, I suggest comparing the observed glade species to what Baskin and Baskin [10] consider to be the most important dolomite glade species. The presence of the most important wildflower species can help us further understand if the recovery of the glade is in a healthy manner. It would be interesting to compile a comprehensive list of all dolomite glade wildflower species. The fact that such a list does not exist, serves as an indication that basic census surveys are fundamental and practical for further investigations. If such a list of expected Ozark dolomite glade wildflower species existed, future research could include a comparison of the wildflowers present in particular nature reserves to the expected list. This could serve as another means of evaluating glade health and restoration effort efficacy. Moreover, the list could be made into a pictorial field guide for species identification of Ozark glade wild- flowers.

Ultimately, if restoration efforts appear sub-optimal, further examination could focus on other parameters of restoration efficacy (i.e. surveys of other types of flora, fauna, and organism-density), other factors reducing restoration efficacy, or alternative restoration methods. If restoration efforts appear effective, future studies should be conducted to support such findings along with how to further optimize restoration efforts. As glades diminish in number, proper restoration efforts are essential. The preservation of the glades' unique ecosystems, biodiversity and natural processes is of great importance.

\section{REFERENCES}

[1] Palmer, M.A., Ambrose, R.F. and Poff, N.L. (1997) Ecological theory and community restoration ecology. Restoration Ecology, 5, 291-300. doi:10.1046/j.1526-100X.1997.00543.X

[2] Nelson, P.W. (1987) Terrestrial natural communities of Missouri. Missouri Department of Natural Resources, Jefferson City.

[3] Radford, T. and Jeffries, A. (2006) Uncovering a gem: Restoring a glade brings forth a resurgence of unique plants and animals. Missouri Conservationist, 67, 23-26.

[4] Martin, P. and Houf, G.F. (1993) Glade grassland in Southwest Missouri. Rangelands, 15, 70-73.

[5] Shaw Nature Reserve (2009) Glade restoration. http://www.shawnature.org/stewardship/GladeRestoratio n.aspx

[6] Kimmel, V.L. and Probasco, G.E. (1980) Change in woody cover on limestone glades between 1938 and 1975 Transaction of the Missouri Academy of Science, 14, 6974.

[7] Arnold, J.F. (1955) Plant life-form classification and its use in evaluating range conditions and trend. Journal of Range Management, 8, 176-181. doi:10.2307/3894219

[8] Van Zandt, P.A., Collins, E., Losos, E.B. and Chase, J.M. (2005) Implications of food web interactions for restoration of Missouri Ozark glade habitats. Restoration Ecol- 
ogy, 13, 312-317. doi:10.1111/j.1526-100X.2005.00039.x

[9] Kurz, D. (1999) Ozark wildflowers: A field guide to common Ozark wildflowers. Guilford Press, Guilford.

[10] Baskin, J.M. and Baskin, C.C. (2000) Vegetation of li- mestone and dolomite glades in the Ozarks and Midwest Regions of the United States. Annals of the Missouri Botanical Garden, 87, 286-294. doi:10.2307/2666165 